\title{
Case Report of Early Release of Penile Strangulation by Metallic Rings
}

\author{
Mohammed Alkhureeb \\ Department of Urology, College of Medicine, Najran University,Najran, kingdom of Saudi Arabia
}

\begin{abstract}
Penile strangulation is rare and usually results following placement of constricting objects to enhance sexual stimulation. It requires urgent treatment as delay may lead to irreversible penile ischemia and gangrene. 30 years old male present to emergency room with acute urine retention secondary to metallic ring strangulation of penis. Patient was taken to operation room to release the ring by open lateral corportomy and string technique. Patient retained his normal voiding and erectile function. Early release of the strangulation leads to preserve the urethral and erectile function.
\end{abstract}

Keywords: Penile Strangulation, Metallic Ring Release

\section{Introduction}

Penile strangulation is rare and usually results following placement of constricting objects to enhance sexual stimulation. It requires urgent treatment as delay may lead to irreversible penile ischemia and gangrene. Various objects causing penile strangulation have been reported. Nonmetallic and thin metallic objects can be removed easily as compared to heavy metallic objects. [1]

A man may place these objects for erotic or autoerotic purpose [4, 9-10], to increase sexual performance [2, 5, 9], as self-treatment of erectile dysfunction [8] and in cases of psychiatric disturbance $[4,11]$.

Removal of these constricting is usually demanding for treating surgeons. Depending on the type of constricting material, special equipment is essential for successful removal of the foreign bodies. We share our experience of managing penile strangulation in this patient.

\section{Case Report}

Thirty year old male. Known case of Psychiatric disorder. He presented to King Fahad central hospital with history of acute urine retention secondary topenile strangulation for $8 \mathrm{Hrs}$. He inserted Heavy Metallic ring since 8HRS for sexual desires purposes. He had no history of erectile dysfunction with normal libidoand ejaculations volume .He had no history of lower urinary tract symptom and no history of hematuria. He had no past medical or surgical history. He is unemployed, unmarried with poor economic status living with his parents. $\mathrm{He}$ is a smoker with history of drug abuse. He has no allergic history; he has no documented Sexual Transmitted Disease or Urethral Discharge

\section{Per Examination}

Patient general condition: he was irritable with poor general hygiene. Cardio Vascular System with normal limits. Chest good bilateral air entry .Abdomen soft with suprapubic tenderness with encourage edematous penis with a metallic ring at the base of penis and normal themeatus [Figure 1].Normal both testes and scrotum. Digital Rectal Exam small non tender with no nodule in the prostate and normal anal tone. Normal neurological exam

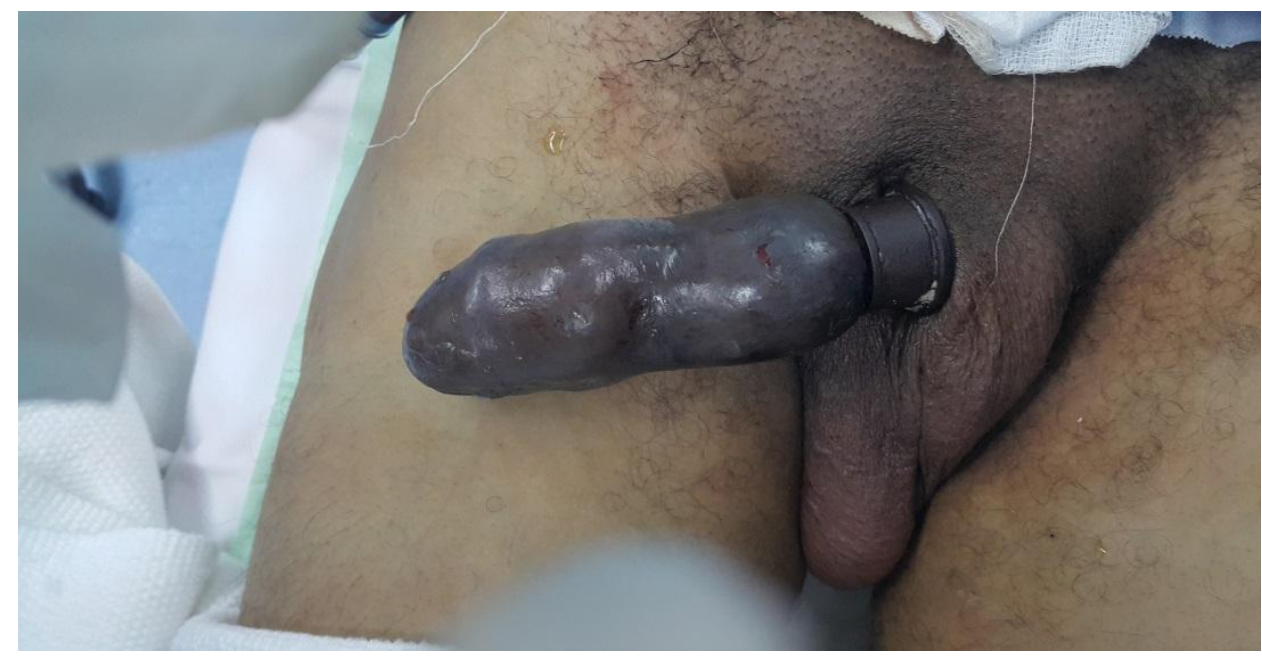

Figure 1 


\section{International Journal of Science and Research (IJSR) \\ ISSN (Online): 2319-7064 \\ Index Copernicus Value (2013): 6.14 | Impact Factor (2014): 5.611}

\section{Investigation}

$\mathrm{CBC}$ with the normal limit. Renal profile with the normal limit and coagulation profile with the normal limit.Ultrasound full bladder and normal upper tract.

Hospital course, Patient was admitted and supra pubic catheter inserted with 1L. Clear urine came out. Afterdiscussion with the patient the emergency removal of the ring and he agreed.

He was taken to the emergency O.R under successful general anesthesia I .v antibiotic was given to the patient in supine position cleaning and draping done try of removing the ring using the lubricant failed to remove it then try of cutting the ring using bone cutter also was not successful then lateral corportomy to release the congested penis done with the use of lubricant we were able to pass the ring distally up to the glans penis [ Figure 2]. The glans penis was congested. And cannot pass the ring, then trial of aspiration was done and were not able to pass the ring, then we used a proline 0 wrapped around the glans penis and passing the distant end under the ring and trial passing the ring over it that was successful to remove the ring completely then dressing was done to the penis [Figure $3 \& 4$ ].Patient tolerates the procedure and shifted to recovery room in good stable condition. The patient was kept in the hospital for one week on antibiotic and dressing bid to the penile area. On the $7^{\text {th }}$ day we clamp supra pubic catheter \& patient voided with no PVR and he was discharge. 1 month later $\mathrm{He}$ was seen in the clinic with history of normal erecting with normal voided.

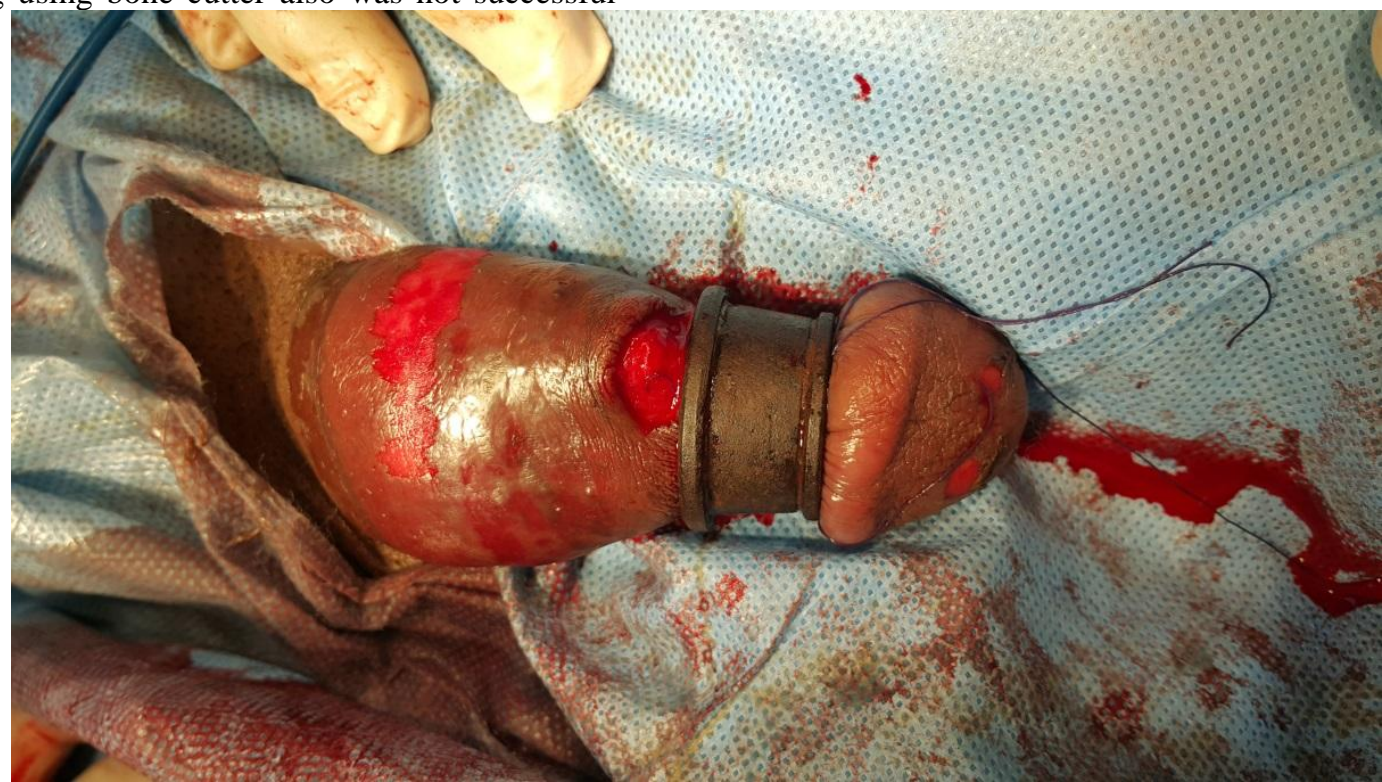

Figure 2

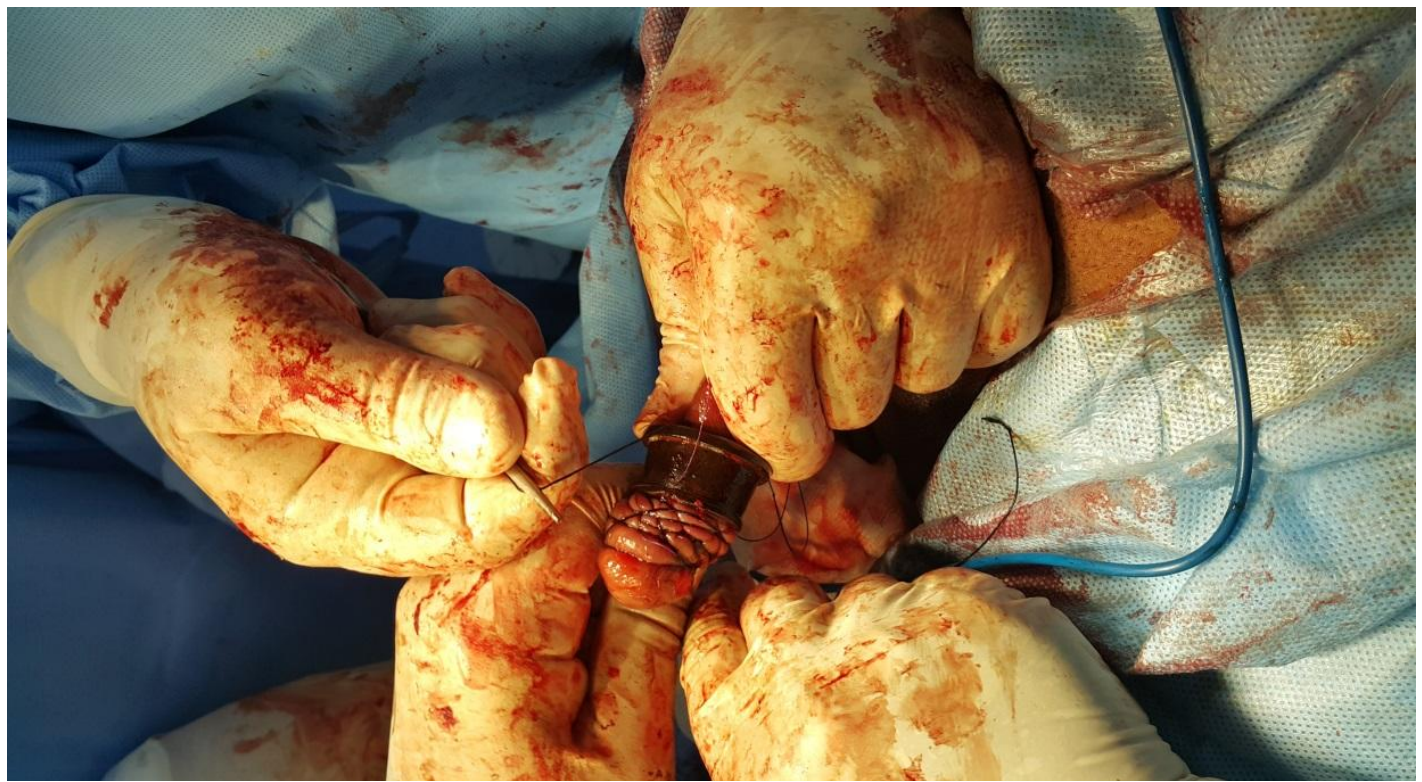

Figure 3 


\section{International Journal of Science and Research (IJSR) \\ ISSN (Online): 2319-7064}

Index Copernicus Value (2013): 6.14 | Impact Factor (2014): 5.611

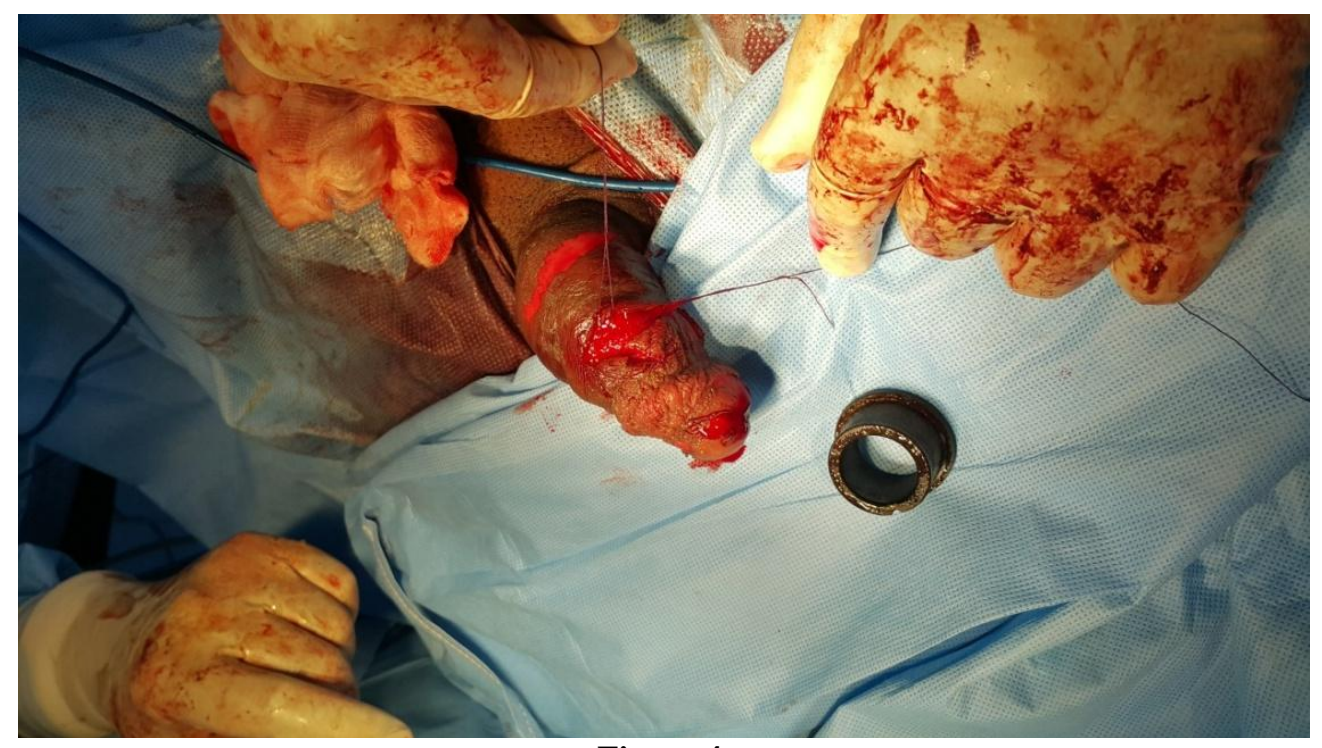

Figure 4

\section{Discussion}

Penile strangulation by metallic rings are not frequent but be most difficult to manage, as may lead to vascular emergency by impeding arterial supply and gangrene may result, leads to amputation, other than penile edema, obstruction in lymphatic flow. Management requires no particular skills but stressed as serious injury and early removal of strangulating object is essential.

AL Bhat et al. (1999) graded these injuries as follows [6]. Grade I Edema of distal penis. No evidence of skin ulceration or urethral injury. Grade II Injury to skin and constriction of corpus spongiosum but no evidence of urethral injury. Distal penile edema with decreased penile sensation. Grade III Injury to skin and urethra but no urethral fistula. Loss of distal penile sensations. Grade IV Complete division of corpus spongiosum leading to urethral fistula and constriction of corpus cavernosa with loss of distal penile sensations. Grade V Gangrene, necrosis, or complete amputation of distal penis.

The choice of method for removal depends upon type, size, incarceration time, trauma grade, and availability of the equipment to remove the constricting object. Prompt diagnosis and early treatment are essential to avoid the potential complications of ischemic necrosis and auto amputation. Removal of such devices is usually challenging and often requires imagination and a multidisciplinary approach [3].

Treatment techniques for penile incarceration can generally be divided into four groups: the string technique and its variants, with and without aspiration of blood from the glans; aspiration techniques; cutting devices; and surgery [7]

After the removal of the object the urethra should be evaluated radiologically. If grade III-V injuries are found, urinary diversion should be done via suprapubic puncture. In grade I and II injuries, simple emptying of the bladder by urethral catheterization maybe required. But more severe cases may require suprapubic cystostomy, urethral reconstruction, degloving and skin grafting or sometimes amputation

\section{References}

[1] Singh $\mathrm{I}^{1}$, Joshi MK, Jaura MS.Strangulation of penis by a ball bearing device.J Sex Med. 2010 Nov;7(11):3793-7. doi: 10.1111/j.1743-6109.2010.01929.x.

[2] Dakin WB. Urological oddities. Los Angeles: University of California Publishers. 1948; p.200,202,208,212,216,218,231,232.

[3] Silberstein, J., Grabowski, J., Lakin, C. and Goldstein, I. (2008) Penile Constriction Devices: Case Report, Review of the Literature, and Recommendations for Extrication. The Journal of Sexual Medicine, 5, 1747-1757. http://dx.doi.org/10.1111/j.1743-6109.2008.00848.x

[4] Perabo FG, Steiner G, Albers P, Muller SC, Treatment of penile strangulation caused by constricting devices. Urology. 2002;59;137.

[5] Silberstein J, Grabowski J, Lakin C, Goldstein I. Penile constricting devices: a case report, review of the literature and recommendations for extrication. J Sex Med. 2008;5(7): 1747-57.

[6] Bhat, A.L., Kumar, A., Mathur, S.C. and Ganwal, K.C. (1991) Penile Strangulation. British Journal of Urology, 68, 618-621. http://dx.doi.org/10.1111/j.1464410X.1991.tb15426.x

[7] Banyra, D., Sheremeta, R. and Shulyak, A. (2013) Strangulation of Penis: Two Case Reports. Central European Journal of Urology, 66, 242-245.

[8] Rana A, Sharma N. Masturbation using metal washers for the treatment of impotence: painful consequences. Br. J Urol. 1994;73:722.

[9] Detweiler MB. Penile incarceration with metal objects: a review of procedure choice based on penile trauma grade. Scand J Urol Nephrol.2001;35:212-17.

[10]Darby JC,David M. Genital incarceration: an unusual case report. Can UrolAssoc. 2010;4(3):E76.

[11] Vahasarj VJ, Hellstorm PA, Serlo W, Kontturi MJ. Treatment of penile incarceration by the string method: 2 case reports. J Urol. 1993; 149: 372-3 